\title{
Bolsa Permanência na UFMS: NOVAS CONFIGURAÇÓES E VELHOS DESAFIOS
}

\author{
Permanence SCHOLARShip in UFMS: \\ NEW CONFIGURATIONS AND OLD CHALLENGES
}

\begin{abstract}
Felipe Vieira Gimenez
Doutorando em Educação pelo Programa de Pós-Graduaçấo em Educação da Universidade Federal de Mato Grosso do Sul, Campo Grande, MS - Brasil. felippegimenezz@gmail.com

Carina Elisabeth Maciel

Doutora em Educação. Professora do Programa de Pós-Graduação em Educação da Universidade Federal de Mato Grosso do Sul, Campo Grande, MS - Brasil. carina22em@gmail.com
\end{abstract}

\begin{abstract}
Resumo: Este artigo tem como objetivo analisar a percepção dos estudantes sobre a ação "Bolsa Permanência" na Universidade Federal de Mato Grosso do Sul/UFMS, campus Campo Grande, como estratégia para favorecer a permanência nos cursos de graduação presencial. O presente texto é resultado de pesquisa realizada em rede e produto de dissertaçáo já defendida, por meio do qual buscamos o desvelamento do real, intrínseco nas práticas sociais e na materialização das políticas educacionais. A pesquisa é de caráter exploratório e tem natureza bibliográfica e documental, apresentando como fontes relatórios e documentos institucionais do MEC e da UFMS para o período 2013, 2014 e 2015. Os resultados indicam que a bolsa permanência, vinculada à política de assistência estudantil na UFMS, constituiu estratégia política que favorece, mas não garante, a permanência dos estudantes no campus universitário por meio de bolsas e auxílios financeiros concedidos no âmbito da ação Bolsa Permanência.

Palavras-Chave: Assistência Estudantil. Educação Superior. Permanência. UFMS.
\end{abstract}

Aвstract: This article aims to analyze the action "Bolsa Permanência UFMS" at the Federal University of Mato Grosso do Sul / UFMS, Campus Campo Grande / MS, as a strategy to favor the permanence in the perspective of the students, in the undergraduate courses. The present text is a result of research carried out in a network and dissertation product already defended, through which we seek the unveiling of the real, intrinsic in social practices and in the materialization of educational policies. The research is exploratory, bibliographical and documentary, presenting as sources reports and institutional documents of the MEC and UFMS for the period 2013, 2014 and 2015. The results indicate that the scholarship permanence linked to the student assistance policy in UFMS was a political strategy which favors, but does not guarantee the permanence of the students in the university campus through scholarships and financial aid granted.

KeYwords: Student Assistance. High Education. Permanence. UFMS. 


\section{Apresentaçáo}

O presente artigo resulta de estudos, investigaçóes e debates promovidos pelo Grupo de Estudos e Pesquisas Políticas de Educação Superior Mariluce Bittar (GEPPES/MB), no âmbito da pesquisa (em andamento) "Política de Educação Superior no Brasil Pós-LDB/1996: Impactos na Região Centro-Oeste", financiada pela Fundação de Apoio ao Desenvolvimento do Ensino, Ciência e Tecnologia do Estado de Mato Grosso do Sul (FUNDECT) e desenvolvida em íntima relação com a pesquisa realizada pela Rede Universitas/Br "Políticas de Expansão da Educação Superior no Brasil", com financiamento do programa de fomento OBEDUC/CAPES/INEP.

O objetivo deste trabalho consiste em analisar a ação "Bolsa Permanência UFMS" na Universidade Federal de Mato Grosso do Sul/ UFMS, campus $^{1}$ Campo Grande/MS, como estratégia para favorecer a permanência, na perspectiva dos estudantes beneficiados por essa ação, nos cursos de graduação presencial nos anos de 2013, 2014 e 2015. O entendimento expresso pelos estudantes será analisado por meio das respostas dadas por eles nos formulários preenchidos após a conclusão da ação. As respostas evidenciam como esses estudantes avaliam os resultados dessa ação com relação à experiência vivenciada.

A pesquisa tem caráter exploratório, abordagem quali-quantitativa e metodologia de coleta de dados documental e bibliográfica. A fonte de dados da pesquisa documental foi o banco de dados da instituição, no qual foram levantados, sistematizados e analisados os seguintes documentos: resoluçóes, leis, decretos, portarias, relatório parcial e anual, relatório de gestão, PDI e, especialmente, (77) formulários de avaliação final da bolsa permanência, preenchidos pelos bolsistas, referentes aos anos 2014 e 2015 . Não tivemos acesso ao formulário do ano 2013, porém a pesquisa abrange três anos (2013, 2014 e 2015), tendo em vista apenas a análise referente à bolsa permanência.

Com base nas leituras da produção acadêmica sobre o tema da permanência estudantil na educação superior e nos dados coletados nos documentos oficiais e nas entrevistas estruturou-se este trabalho em duas partes. Na primeira é feita uma contextualização do conceito de permanência e dos critérios de seleção dos estudantes bolsistas, tendo 
como aporte os documentos institucionais citados e os decretos e leis que normatizam a bolsa permanência nas universidades federais e na UFMS, locus de nossa pesquisa.

Em seguida, serão apresentados os resultados da pesquisa da ação Bolsa Permanência UFMS com dados relativos aos estudantes atendidos nos anos de 2013, 2014 e 2015, indicando percentual de bolsistas por unidade acadêmica na UFMS e analisando as respostas dos estudantes bolsistas na avaliação final da ação. A questão em pauta é analisar se os estudantes contemplados consideram que a bolsa garante a permanência e a conclusão do curso. Por fim, são analisados os dados apresentados em gráfico (1 e 2) e as percepçóes dos estudantes.

\section{Políticas de educação superior: a permanência em foco na UFMS}

Investigar políticas e ações voltadas à permanência dos estudantes na Educação Superior implantadas nos últimos anos, no contexto das universidades federais brasileiras, implica apontar relaçôes e resultados de programas ou açóes específicas, assim como definir os termos que sustentam tais programas e ações.

Nesse entendimento, Cordeiro e Cordeiro (2015) entendem a permanência como uma política institucional, um compromisso que a instituição assume para evitar/diminuir a evasão de estudantes e que procura ir além da mera preocupação com números; cabe, para os autores, criar um espaço de relaçóes na universidade que leve em conta a diversidade de perfil dos/as estudantes, de modo que desempenhe a função social da instituição pública de promoção da cidadania. A política de permanência está condicionada a fatores, externos e internos, que são inerentes ao contexto do estudante. Segundo Maciel, Silva e Veloso (2015, p. 265), “[...] cumpre assinalar o entendimento expresso em documentos nacionais de que a permanência do estudante na educação superior associa-se a investimentos na assistência estudantil."

Nesse contexto, segundo o Plano de Desenvolvimento Institucional (PDI 2015-2019), a UFMS embasa-se na Política Nacional de Assistência Estudantil (PNAES), que tem como objetivo propiciar o acesso, a perma- 
nência e a conclusão do curso de seus estudantes visando inclusão social, formação ampliada, produção de conhecimento e melhoria do desempenho acadêmico e da qualidade de vida. Esse documento institucional é entendido como "[...] um instrumento de planejamento de uma instituição, espaço em que se definem os objetivos e as metas de desenvolvimento para longo prazo, bem como as açôes necessárias à concretização do planejamento estratégico." (UFMS, 2015a, p. 9)

Para a execução dos objetivos estabelecidos, a universidade atua em quatro áreas estratégicas, que por sua vez são desenvolvidas por meio de programas e projetos fundamentados em metas quantificáveis. São elas: permanência; desempenho acadêmico; cultura, lazer e esporte e assuntos da juventude. As açôes realizadas em cada área estratégica da assistência estudantil são baseadas nos seguintes princípios norteadores, em conformidade com o Plano Nacional de Assistência Estudantil:

a) afirmação da educação superior como uma política de Estado; b) gratuidade do ensino; c) igualdade de condiçóes para o acesso, a permanência e a conclusáo de curso nas IFES; d) formação ampliada na sustentação do pleno desenvolvimento integral dos estudantes; e) garantia da democratização e da qualidade dos serviços prestados à comunidade estudantil; $f$ ) liberdade de aprender, de ensinar, de pesquisar e de divulgar a cultura, o pensamento, a arte e o saber; g) orientação humanística e a preparação para o exercício pleno da cidadania; h) defesa em favor da justiça social e a eliminação de todas as formas de preconceitos; e i) pluralismo de ideias e o reconhecimento da liberdade como valor ético central. (UFMS, 2015a, p. 56)

Desse modo, a política de assistência estudantil da UFMS, como processo educativo, dever articular-se ao ensino, à pesquisa e à extensão, auxiliando na formação de cidadãos qualificados e comprometidos com a sociedade e sua transformação. Permear essas três dimensôes do fazer acadêmico significa viabilizar o caráter transformador da relação universidade e sociedade. Inseri-la na práxis acadêmica implica entendê-la como direito social, rompendo com a ideologia tutelar do assistencialismo, da doação, do favor e das concessôes. (UFMS, 2015a) 
A UFMS busca redimensionar as ações desenvolvidas implementando programas existentes e implantando novas ações a partir das áreas estratégicas e das linhas temáticas definidas no PNAES. Tal processo não se efetiva apenas no acesso à educação superior gratuita, mas abrange a criação de mecanismos que viabilizem a permanência e a conclusão do curso, reduzindo os efeitos das desigualdades apresentadas por um conjunto de estudantes provenientes de segmentos sociais em situaçáo de vulnerabilidade e que apresentam dificuldades concretas de prosseguirem sua vida acadêmica com sucesso.

No artigo 2o da Resolução no 7, de 6 de fevereiro de 2015, preconiza-se que a ação Bolsa Permanência integra a Política de Assistência Estudantil da UFMS e se destina aos estudantes em situação de vulnerabilidade socioeconômica regularmente matriculados em curso de graduação presencial da Fundação Universidade Federal de Mato Grosso do Sul. Sobre o financiamento, o artigo $3^{\circ}$ dispóe que "Os recursos financeiros utilizados para a execução da Ação estão assegurados no Programa Nacional de Assistência Estudantil (Pnaes)." (UFMS, 2015c) Sobre o objetivo da ação, o artigo $5^{\circ}$ estabelece que ela

[...] tem por objetivo auxiliar financeiramente o acadêmico em situação de vulnerabilidade socioeconômica, de forma a garantir a sua permanência na Universidade e contribuir para sua formação integral, buscando reduzir os índices de retenção e evasão decorrentes de dificuldades de ordem socioeconômica. (UFMS, 2015c, p. 4)

A Bolsa Permanência é uma ação vinculada à política de assistência estudantil, sendo oportuno mostrar quantos estudantes são beneficiados por ela, tanto no campus local quanto nos campi do interior, para a partir daí analisar os resultados dessa política. Cabe esclarecer que tal ação, regulamentada em 2009 pelo MEC, já existia dentro do campus, configurada até então como 'bolsa trabalho'. O Decreto no 7.416, de 30 de dezembro de 2010, regulamenta o artigo 10 da Lei ${ }^{\circ} 12.155$, de 23 de dezembro de 2009, que autoriza as instituiçôes federais de educação superior a concederem bolsas a estudantes matriculados em cursos de graduação, para o desenvolvimento de atividades de ensino e extensão, por meio de duas 
modalidades distintas: bolsas permanência e bolsas de extensão, assim definidas em seus objetivos:

I - bolsas de permanência, para a promoção do acesso e permanência de estudantes em condiçôes de vulnerabilidade social e econômica; e II - bolsas de extensáo, para o desenvolvimento de atividades de extensão universitária destinadas a ampliar e fortalecer a interação das instituições com a sociedade. (BRASIL, 2009, grifos nosso)

Sobre a forma de pagamento, o artigo $2^{\circ}$ determina que as bolsas de permanência e de extensão serão pagas mensalmente e adotarão como referência os valores das bolsas de mesma modalidade das agências oficiais de fomento à pesquisa. Com relação o tempo de permanência na ação, fica indicado que essas bolsas poderão ser renovadas, observados a disciplina própria da instituiçáo e os termos do edital de seleçáo e considerado o desempenho do estudante, a avaliaçáo dos programas ou projetos desenvolvidos, bem como a disponibilidade orçamentária.

No que diz respeito ao cancelamento da bolsa, o decreto estabelece os seguintes critérios:

Art. $4^{\circ}$ As bolsas de permanência e de extensão serão canceladas

nos seguintes casos:

I - conclusão do curso de graduação;

II - desempenho acadêmico insuficiente;

III - trancamento de matrícula;

IV - desistência da bolsa ou do curso;

$\mathrm{V}$ - abandono do curso; ou

VI - prática de atos não condizentes com o ambiente universitário, nos termos da disciplina própria da instituição, garantida a ampla defesa e o contraditório. (BRASIL, 2010, grifo nosso)

Com relação à fiscalização da bolsa: 
Art. $5^{\circ} \mathrm{A}$ concessão das bolsas de permanência de que trata art. $1^{\circ}$, inciso I, será disciplinada pelo órgáo colegiado competente da instituição, em harmonia com a política de assistência estudantil, considerada a especificidade das demandas acadêmicas geradas pela vulnerabilidade social e econômica dos estudantes. Parágrafo único. A concessão das bolsas de permanência deverá ser periodicamente avaliada quanto à efetiva ampliação da permanência e ao sucesso acadêmico de estudantes em condição de vulnerabilidade social e econômica na instituição. (BRASIL, 2010)

Quanto aos critérios de recebimento, o artigo $3^{\circ}$ destaca que o candidato às bolsas de permanência e de extensão obedecerá aos seguintes requisitos, sem prejuízo de outros específicos fixados pela instituição:

Art. $3^{\circ}$ Aplicam-se ao candidato às bolsas de permanência e de extensáo os seguintes requisitos, sem prejuízo de outros específicos fixados pela instituição: I - estar regularmente matriculado em curso de graduação; II - apresentar indicadores satisfatórios de desempenho acadêmico, definidos pela instituição; III - ser aprovado em processo de seleção, que deve considerar critérios de vulnerabilidade social e econômica, no caso da bolsa permanência; IV - não receber qualquer outra bolsa paga por programas oficiais; e $\mathrm{V}$ - apresentar tempo disponível para dedicar às atividades previstas no edital de seleção, quando a modalidade exigir. (BRASIL, 2010, grifo nosso)

Nota-se que as modalidades mencionadas - bolsa permanência e bolsa extensão - têm objetivos distintos na IES: enquanto uma utiliza como critério de seleção a vulnerabilidade social e econômica para 'garantir' a permanência, a outra toma a participação nas atividades de extensão como principal critério para o recebimento. Náo foi encontrado no decreto nada que explique ou defina as atividades que os bolsistas da bolsa permanência deverão assumir; apenas apresentam-se os critérios de avaliaçáo, supervisão e cancelamento do processo, seja por meio da conclusão do curso de graduação seja por desempenho acadêmico insuficiente, trancamento de 
matrícula, desistência, abandono de curso e prática de atos não condizentes com o ambiente universitário. Não consta normatização da política de acompanhamento do estudante bolsista na IES.

Nos documentos é possível identificar que caberá à instituição elaborar editais de seleção dos bolsistas, definindo mecanismos, critérios seletivos e número de vagas da açáo por campus, de acordo com o orçamento recebido pela instituição advindos do PNAES.

No item a seguir, destacaremos a ação bolsa permanência e os estudantes atendidos por ela, haja vista que consiste em estratégia de permanência do estudante bolsista na referida instituição.

\section{A açáo Bolsa Permanência na UFMS e os estudantes atendidos}

A permanência de estudantes nas instituições de educação superior é determinada por diferentes ações. Uma delas, desenvolvida na UFMS, é a ação Bolsa Permanência, organizada com base nas orientaçóes do PNAES da educação superior nacional. Tendo com fundamento as políticas nacionais, as instituiçóes federais se organizam de forma peculiar em detrimento de seu contexto regional. Sob essa perspectiva, a UFMS desenvolveu a ação bolsa permanência com critérios específicos, mas determinados pela política nacional em vigor mencionada.

Segundo a Resolução no 7, de 6 de fevereiro de 2015, de foro interno da UFMS, que regulamenta a ação Bolsa Permanência e esclarece sua natureza e finalidade, ela representa uma política de assistência estudantil dessa universidade destinada aos acadêmicos em situação de vulnerabilidade socioeconômica e regularmente matriculados em curso de graduação presencial da Fundação Universidade Federal de Mato Grosso do Sul. A ação se efetiva por meio de auxílio financeiro mensal e adota como referência os valores das bolsas pagas pelas agências oficiais de fomento à pesquisa, conforme Decreto $n^{\circ} 7.416$, de 30 de dezembro de 2010, devendo o valor ser informado por meio de edital de seleção. Os recursos financeiros utilizados para a execução da Ação estão assegurados no Programa Nacional de Assistência Estudantil (Pnaes). (UFMS, 2015c) 
Considerando a ação bolsa permanência especificamente na UFMS, as respostas indicadas nos formulários de avaliação expressam as percepçôes dos estudantes bolsistas com relação ao recebimento das bolsas e à permanência em seus respectivos cursos de graduação. Assim, a investigação se fundamentou na leitura atenta do formulário de avaliação final da ação Bolsa Permanência UFMS, de preenchimento do bolsista. A questão que orientou a investigação se expressa da seguinte forma: A Bolsa Permanência UFMS pode ser considerada como estratégia que favorece a permanência do estudante bolsista na referida instituição?

Foi delimitado como período de análise 2013 e 2015, tendo em vista o contexto das mudanças institucionais na UFMS, tais como: alteração nos critérios de seleção dos bolsistas e ampliação, segundo os documentos regulatórios de normatização e financiamento, de recursos financeiros para o pagamento de bolsas oferecidas por meio da política de assistência estudantil dessa universidade. A seleção objetiva inserir os estudantes regularmente matriculados nos cursos de graduação presencial da UFMS nas açôes da assistência estudantil com vistas à promoção de sua permanência.

As ações do Programa de Assistência Estudantil na UFMS são administradas pela Pró-Reitoria de Assuntos Estudantis (Proaes) e pela Secretaria de Apoio para Assuntos Estudantis (Secaes), tendo como base a alteração recente da Resolução no 59 de 25 de julho de 2017 do Conselho Universitário da UFMS, e compreendem as seguintes açôes: Auxílio Permanência; Auxílio Alimentação; Auxílio Creche; Auxílio Moradia; Auxílio à Participação em Eventos; Auxílio Instrumental Pedagógico e Auxílio Emergencial.

$\mathrm{Na}$ Tabela 1 é apresentada a distribuição da Bolsa Permanência nos campi da UFMS. Ela registra o número de estudantes atendidos pela ação Bolsa Permanência UFMS, por curso e campus, assinalando 395 (trezentos e noventa e cinco) em 2013; em 2014, foram 494 (quatrocentos e noventa quatro), e em 2015, 362 (trezentos e sessenta e dois) estudantes, ou seja, todos os bolsistas tiveram suas bolsas renovadas no ano de 2015, pois neste ano não houve processo seletivo para seleçáo de novos bolsistas, apenas edital de renovação. 
Tabela 1: Número de estudantes atendidos pela Bolsa Permanência nos campi/UFMS entre 2013 e 2015

\begin{tabular}{c|c|c|c}
\hline \multirow{2}{*}{ CAMPUS } & \multicolumn{3}{|c}{ Bolsa Permanência/UFMS } \\
\cline { 2 - 4 } & $\mathbf{2 0 1 3}$ & $\mathbf{2 0 1 4}$ & $\mathbf{2 0 1 5}$ \\
\hline Cidade Universitária - Campo Grande & 395 & 494 & 362 \\
\hline Câmpus de Aquidauana - CPAQ & 200 & $*$ & 147 \\
\hline Câmpus de Bonito - CPBO & 08 & 8 & 09 \\
\hline Câmpus de Chapadáo do Sul - CPCS & 40 & 37 & 40 \\
\hline Câmpus do Pantanal - CPAN & 194 & 145 & 180 \\
\hline Câmpus de Coxim - CPCX & 80 & 75 & 131 \\
\hline Câmpus de Naviraí - CPNV & 50 & 18 & 28 \\
\hline Câmpus de Nova Andradina - CPNA & 58 & 55 & 69 \\
\hline Câmpus de Paranaíba - CPAR & 55 & 45 & 54 \\
\hline Câmpus de Ponta Porã - CPPP & 40 & 32 & 40 \\
\hline Câmpus de Três Lagoas - CPTL & 180 & 141 & 210 \\
\hline TOTAL & 1.300 & 1.050 & 1.270 \\
\hline
\end{tabular}

* Segundo o edital PREAE no 24/2014 que tornou público o resultado final da renovação da participação nas Açôes de Assistência Estudantil para o ano de 2014, exceto para o Campus de Aquidauana.

Fonte: Edital no 09/2013-PREAE processo seletivo das açōes de assistência estudantil da UFMS; Anuário de informaçōes e estatísticas UFMS 2012/2014. Elaboração dos autores.

Nesse contexto, em consulta ao Relatório de Gestão dos anos 2013 a 2015, constatou-se que a Bolsa Permanência apresenta uma demanda maior de inscritos no período analisado. Fica registrado, no ano de 2014, somados os números da cidade universitária e de outro campus ${ }^{4}$ do interior, um total de 3.306 estudantes inscritos no processo seletivo para a açáo Bolsa Permanência UFMS, sendo: 919 estudantes que participaram do processo de renovaçáo, 1.712 estudantes que participaram do $1^{\circ}$ processo seletivo e 675 estudantes que participaram do $2^{\circ}$ processo seletivo. Do total de 3.306 estudantes solicitantes, 1.050 foram contemplados com a ação, significando um alcance de $58 \%$ no número de estudantes atendidos em relação à demanda. No ano de 2015, 1.270 estudantes tiveram seus benefícios (Bolsa Permanência) renovados. (UFMS, 2015b) 
Porém, em razão da extensa greve ocorrida nas IFES, bem como do envio tardio do orçamento, não foi possível a realização dos processos seletivos 1 e 2, ocorrendo apenas o processo de renovação da ação. Dessa forma, justifica-se que, em razão da ausência do número da demanda oriunda dos dois processos seletivos de 2015, a equipe multiprofissional, composta de assistente social, psicólogo e técnico em assuntos educacionais (TAE), ficou impossibilitada de mensurar o aumento do alcance da ação, uma vez que não há número de demanda, tampouco de atendidos em novos processos seletivos. O processo de renovação foi possível a partir da instituição dessa equipe multiprofissional e a efetivação do acompanhamento aos estudantes beneficiários das ações de assistência estudantil, que a partir do Decreto no 7.234,/2010, que dispóe sobre o Pnaes, garantiu que os estudantes de graduação tivessem prioridade no acesso às açóes de assistência estudantil e permanecessem até a sua graduação. Em 2014, a Coordenadoria de Assistência Estudantil, vinculada à Pró- Reitoria de Extensão, Cultura e Assuntos Estudantis, objetivando garantir assistência plena, propiciou que os estudantes inseridos nas Ações de Assistência Estudantil no ano de 2013 tivessem seus benefícios renovados para os anos de 2014 e 2015. (UFMS, 2016a)

Os altos índices de indeferimento são apontados no Relatório de Gestão como documentação incompleta e preenchimento incorreto do formulário. Nesse sentido, a equipe multiprofissional propôs alteração no edital de seleção para os benefícios assistenciais. Facilitaram o preenchimento com uma escrita mais clara e detalhada, disponibilizaram os modelos dos documentos em anexos e alterou os critérios para acesso às açôes, que passou a ser por um sistema de pontuação que permitiu ranquear os estudantes com perfil para bolsa.

Segundo os dados do Gráfico 1, que registra o percentual de bolsistas por unidade acadêmica na UFMS, os centros (CCHS e CCBS) totalizam 53\% dos bolsistas, ou seja, mais da metade dos estudantes estáo concentrados nos cursos das áreas humanas e biológicas. As faculdades (FACOM, FADIR, FAENG, FAODO, FAMEZ e FAMED) agrupam $32 \%$ do total, e os institutos (INFI, INMA e INQUI) são minoria, com apenas $13 \%$ dos bolsistas. A ESAN aparece com 1\%, haja vista que integra o curso de graduação presencial de Administração-Bacharelado. 


\section{Percentual de bolsistas por unidade acadêmica na UFMS (2013-2015)}

2013-2015

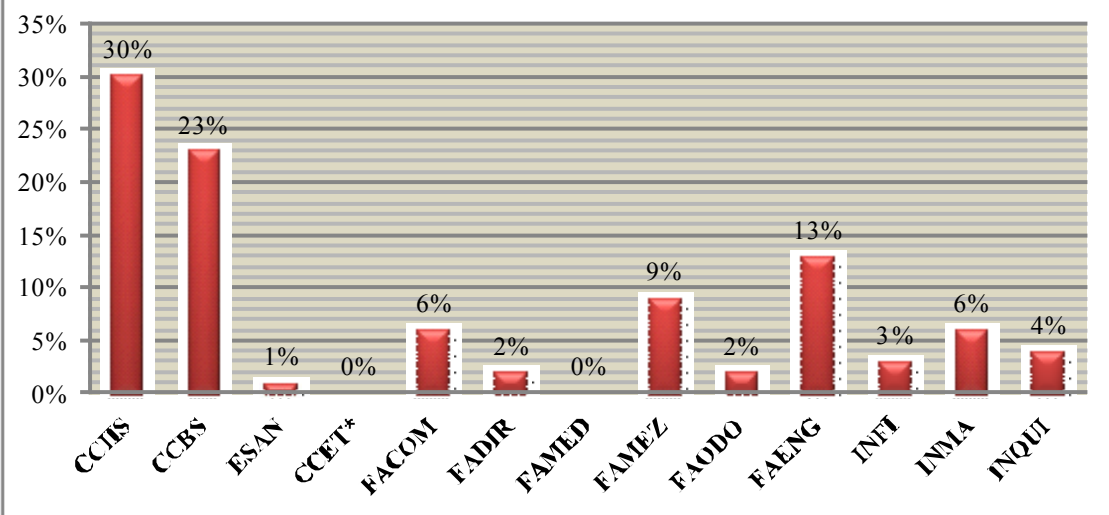

\section{Gráfico 1}

* Centro extinto em 2013.

Fonte: PREAE/UFMS. Elaboração dos autores.

Com relação aos cursos, a Bolsa Permanência abrangeu, entre 2013 
A terceira unidade, FAENG, em 2013 abrangeu 43 estudantes, em 2014, foram 61, e em 2015, 57 bolsas renovadas, média de 13\%. Os institutos (INQUI, INFI E INMA) registraram, respectivamente, 50 bolsistas em 2013, 71 em 2014 e 48 em 2015, com média de 13\%.

O curso de medicina contava em 2013 com três bolsistas; em 2014 e 2015 não apareceu mais bolsista, e como não tivemos acesso aos desligamentos do período de 2013, não foi possível constatar os motivos.

O Gráfico 2 registra as respostas encontradas no formulário de avaliação final da ação Bolsa Permanência/UFMS relacionadas a se o estudante considera que a ação Bolsa Permanência atinge o objetivo de propiciar a permanência e conclusão de curso dos estudantes.

\section{Você considera que a Ação Bolsa Permanência proporciona a permanência e conclusão de curso dos acadêmicos?}

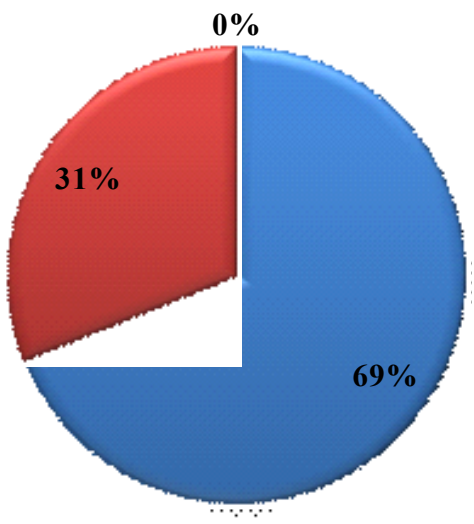

Sim, to ta lmente

$\mathbf{S i m}$, pa rcialmente

滈Não

Gráfico 2: Percentual de respostas dos estudantes bolsistas na avaliação final da Bolsa Permanência

Fonte: PREAE/DIAA/CAE. Elaboração dos autores.

Sobre o percentual apresentado, cabe destacar que a maioria das respostas $(69 \%)$ considera a Bolsa Permanência uma ação que propicia a permanência e a conclusão do curso. No entanto, 31\% das respostas indicam que isso acontece parcialmente, apresentando algumas justificativas. 
Não houve nenhuma resposta negativa. Entres os motivos descritos pelos estudantes com relação à opção 'sim, parcialmente' e sua relação com os respectivos cursos, estáo:

Náo é fator determinante para a permanência de um aluno em seus estudos (Administração).

A exigência curricular poderia ser maior. (Engenharia de Computação)

Deve haver maior atenção às exigências de estudantes que são de fora do estado de MS (moradia, alimentaçáo noturna e etc). Não moro sozinho, mas conheço isso através de outros colegas. (Ciências Sociais)

Se o auxílio fosse um pouco maior, ajudaria mais o custeio da vida do acadêmico. (Geografia-Bacharelado)

O auxílio não é suficiente para cobrir totalmente os gastos. (Pedagogia)

Paga-se um valor baixo. (Ciências Sociais)

É uma ajuda para alguns gastos com a faculdade, mas não supre todas as necessidades do aluno principalmente para quem faz curso integral. (Nutrição)

Porque o edital demora em sair, o que torna o período da bolsa menor, meio ano apenas. (Fisioterapia) (UFMS, 2014, grifos nossos; GIMENEZ, 2017, p. 273)

Assim, o que se pode destacar, nas críticas dos estudantes à ação sobre o que dificulta a permanência do estudante, é a falta de apoio e suporte àqueles que vêm de outra região/estado/cidade, pois a Cidade Universitária não possui moradia estudantil e a Bolsa Permanência é incluída como uma ação de moradia. Os estudantes consideram esse valor baixo e descreveram que o mesmo não cobre totalmente as despesas. A burocracia é outro elemento criticado, pois o tempo de divulgação do edital até o recebimento do primeiro pagamento leva em torno de 5 (cinco) meses, resultando em pelo menos um mês do ano sem recebimento da bolsa.

No mesmo formulário há duas perguntas dissertativas com relação a pontos positivos e negativos da ação Bolsa Permanência. Inicialmente destacamos os pontos positivos que representam elementos indicativos de 
favorecimento da permanência no curso. Os fatores negativos, que não favorecem a continuidade do estudante bolsista na instituição, são descritos a seguir. Pode-se eleger para análise fatores internos e externos. Este estudo apontou para os elementos que podemos identificar como internos como a maior participação em eventos científicos e o contato com atividades relacionadas à escolha de sua profissão, à compra de materiais didáticos, isto é, contempla um mínimo básico para permanência na instituição. Os elementos que não favorecem a permanência são o baixo valor da bolsa, a falta de um programa de moradia com espaço físico que possa atender estudantes de outras cidades e estados, a burocracia dos processos de seleção, a demora no recebimento do primeiro pagamento e maior incentivo à pesquisa. Nesse âmbito, o fator financeiro é um dos elementos essenciais para se pensar em políticas de permanência com qualidade e responsabilidade para favorecer e incentivar este estudante a permanecer em seu curso de graduação.

Há um conjunto de elementos elencados pelos estudantes bolsistas que podem ser tanto externos quanto internos e que, inseridos em determinados contextos, fazem garantir sua conclusáo. Maciel, Lima e Gimenez (2016, p. 775) destacam que,

Embora o aspecto econômico seja importante para favorecer, ou não, a permanência do estudante em seu respectivo curso, partimos da premissa de que não seja o único ou o preponderante. Dessa forma, entendemos que as políticas assistencialistas focais são essenciais ao público de baixa renda; contudo, deve se considerar a complexidade da questão que permeia a permanência. [...] Ao se tratar do debate da permanência, mesmo reconhecendo os méritos de uma política assistencial, estrategicamente, almejamos uma política social de cunho universal, visto que esta se voltaria para açóes mais abrangentes que generalizam o atendimento, o que pode possibilitar uma participação ativa de todos os estudantes na vida acadêmica.

A condiçáo socioeconômica é a que representa maior peso para que o candidato à bolsa seja selecionado, uma vez que o objetivo principal da ação é auxiliar financeiramente o estudante visando garantir sua per- 
manência e reduzir índices de evasão e retenção. De acordo com as informaçôes escritas nos formulários, os bolsistas utilizam o dinheiro para: alimentação, despesas domésticas (água, luz e telefone), moradia (aluguel), transporte, instrumentos específicos de seu curso de graduação. Neste caso, um acadêmico do curso de Odontologia afirmou que utilizou o pagamento da bolsa para comprar e reproduzir material didático (xerox, livros e apostilas) e para participar de congressos e seminários.

As sugestóes apresentadas pelos estudantes bolsistas se dirigem a propor aumento do valor da bolsa e aumentar a duraçáo de sua vigência; implantar moradia estudantil; ampliar o incentivo a projetos de pesquisa; diversificar parcerias com outras instituiçôes para possibilitar estágios profissionais, para diminuir a dependência e não se ter que ficar pura e simplesmente em uma política de "assistência".

Segundo estudos de Borsato (2015), a assistência estudantil, no período anterior ao PNAES, ficou marcada por açóes pontuais, muitas das quais dependiam, para sua realização, das parcerias estabelecidas com fundações de apoio e empresas, como é o caso da Bolsa-Alimentação e do Auxílio-Moradia. Em virtude dos escassos recursos e como consequência disso a oferta de poucas vagas, as açóes eram focalizadas no atendimento do público com menor renda familiar e era nisso que se concentrava o trabalho dos poucos assistentes sociais: fazer a seleçáo dos acadêmicos.

Com a chegada dos recursos do PNAES, novas açóes foram organizadas nos campi da UFMS, dentre elas a ação denominada Bolsa Permanência. No regulamento dessa ação, Resolução no 64, de 27 de novembro de 2012, é esclarecida sua natureza e finalidade e se dispóe que ela não é cumulativa com outras bolsas oferecidas pela UFMS ou pagas por programas oficiais com a mesma finalidade. (UFMS, 2016b) Ocorre que a ação Bolsa Permanência foi criada em substituição a Bolsa de Trabalho Interno, por meio da Resoluçáo no 31, de 8 de julho de 2008, como forma de contribuir financeiramente com o acadêmico para que ele possa custear suas despesas pessoais de alimentaçáo e moradia. Os valores estabelecidos eram de 59\% do salário mínimo para os acadêmicos da Cidade Universitária e 72,6\% do salário mínimo para os demais campi. Essa diferença era justificada pela existência de transporte coletivo $100 \%$ gratuito em Campo Grande. (BORSATO, 2015) Com a Bolsa Permanência, os acadêmicos precisariam cumprir doze horas semanais em projetos de en- 
sino, pesquisa e extensão, escolhidos por eles de acordo com seu perfil e interesse.

Existem na UFMS outras açôes na forma de bolsas, programas e auxílios de fomento interno e externo que contribuem para a permanência do estudante no curso. Destacam-se como bolsas as ações: Bolsa Extensão Universitária/UFMS; Bolsa Promisaes; os programas Bolsa Permanência (PBP /MEC); Programa de Educação Tutorial (PET); Programa de Monitoria de Ensino da Graduação; Programa Institucional de Bolsas de Iniciação à Docência (PIBID), voltado aos cursos de licenciatura; Programa Institucional de Bolsas de Iniciação em Desenvolvimento Tecnológico e Inovação (PIBITI); Programa Institucional de Bolsas de Iniciação Científica/CNPq (PIBIC); UFMS-Voluntários e Programa Institucional

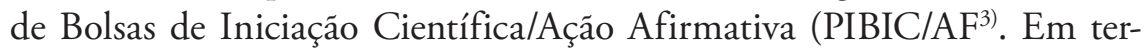
mos de auxílios, temos: Auxílio Alimentação; Auxílio Emergencial; Suporte Instrumental/KIT; Incentivo à Participação em Eventos (IPEV). $\mathrm{Na}$ forma de subsídios pontuam os restaurantes universitários da Cidade Universitária/UFMS e de Três Lagoas. Implica inferir que a política de permanência está condicionada a outros fatores e condicionantes, externos e internos, que são inerentes ao contexto do estudante, corroborando Maciel, Silva e Veloso (2015, p. 265) no sentido de que "[...] o entendimento expresso em documentos nacionais de que a permanência do estudante na educação superior associa-se a investimentos na assistência estudantil."

Tendo como base esses registros, cabe destacar a necessidade de conhecer mais de perto a realidade dos estudantes bolsistas, numa análise que perpassa sua condição de estudante, no interesse de mostrar outros efeitos relacionados à natureza de sua trajetória acadêmica, marcada por processos de inclusão e exclusão. $\mathrm{O}$ fato é que não sabemos quantos processos seletivos esses estudantes realizaram até ingressar na universidade e se, de fato, puderam escolher o curso pretendido, o que nos leva a indicar a necessidade de pesquisar e aprofundar as análises do perfil dos estudantes bolsistas e não bolsistas.

O contexto atual determina a necessidade de fortalecimento e debate sobre as açóes de assistência aos estudantes nas universidades, uma vez que, segundo Sguissardi (2014), o acesso à educação superior não está democraticamente ao alcance de todos, por diversos fatores: desigualdade social, renda familiar, cor/etnia, condição socioeconômica e cultural 
etc. Os conceitos presentes nos documentos oficiais e relatórios de gestão da UFMS permitem uma reflexão sobre sentido e alcance das políticas de permanência; apresenta-nos os princípios de uma universidade e assim problematiza as políticas de permanência, indagando suas contradiçóes e, a despeito de não garantir a permanência, cria estratégias para favorecer, estimular e incentivar financeiramente. No entanto, ao mesmo tempo mascara outro problema social, a desigualdade, e não garante a integração social nem se preocupa com as singularidades dos indivíduos bolsistas.

A breve análise aqui desenvolvida, baseada nos dados do período entre 2013 e 2015, indica que, para superar tais problemas, cabe manter ações institucionais sistemáticas e consistentes no âmbito do planejamento e da gestáo, avaliando os resultados das recentes açôes voltadas à permanência na sua articulação com programas e açôes outros cujo desenho e objetivos já estão determinados na Política Nacional de Assistência Estudantil.

\section{Consideraçóes finais}

As políticas de bolsas visando a permanência dos estudantes na edu- 
favorecem a permanência, quais sejam: valor baixo da bolsa; inexistência de um programa de moradia que atenda a estudantes de outras cidades e estados; burocratização dos processos de seleção; demora no recebimento do primeiro pagamento; descontinuidade das açóes desse tipo e falta de maior incentivo à pesquisa.

Dessa forma, a política de assistência estudantil tem o papel de mobilizar recursos de forma a garantir a permanência e o percurso acadêmico dos estudantes que financeiramente se encontram com dificuldades de realizar e concluir o curso de graduação, com prejuízos para seu processo de formação profissional e cidadã. As açôes estão voltadas a um determinado público, selecionado a partir de critérios como: estar regularmente matriculado em curso de graduação presencial da Fundação Universidade Federal de Mato Grosso do Sul; possuir renda per capita de até um salário mínimo e meio vigente; ter sido selecionado em processo de seleção para o número de vagas ofertadas; não ter concluído curso de graduação e não possuir pendências administrativas nas unidades da Administração Central ou na Secretaria de Apoio para Assuntos Estudantis (SECAE) em que está matriculado.

A análise dos dados permitiu concluir que ação Bolsa Permanência na UFMS, uma vez relacionada a programas de Assistência Estudantil, sofre seus reajustes financeiros, estruturais e políticos e, nessa medida, mostra-se frágil diante de outras problemáticas que atingem os graduandos da educação superior, afetando as políticas existentes de permanência e não atingindo, totalmente, seu objetivo final de conclusão com sucesso dos cursos pelos estudantes. No entanto, os dados também revelam que essa ação representa importante mecanismo estratégico de permanência e conclusão do curso para aqueles que persistem na vida acadêmica, em especial por seu caráter contínuo e articulado a um sistema de demanda pública específica presente nas políticas de Estado e/ou de governo.

\section{Notas}

1 As açôes de assistência estudantil abrangem os campi de Campo Grande/Cidade Universitária; Aquidauana/CPAQ; Pantanal/CPAN; Três Lagoas/CPTL; Coxim/CPCX; Paranaíba/CPAR; Chapadão do Sul/ CPCS; Nova Andradina/ CPNA; Ponta Porā/ CPPP e Naviraí/ CPNV.

2 Art. 1O Programa Nacional de Assistência Estudantil - PNAES, executado no âmbito do Ministério da Educação. Decreto no 7.234, de 19 de julho de 2010. Dispóe sobre o Programa 
Nacional de Assistência Estudantil - PNAES. Disponível em: <http://www.planalto.gov.br/ ccivil_03/_ato2007-2010/2010/decreto/d7234.htm>. Acesso em: 21 abr. 2016.

3 O Programa Institucional de Iniciação Científica - PIBIC nas Ações Afirmativas - PIBIC - AF é dirigido às universidades públicas que são beneficiárias de cotas PIBIC e que têm programa de açôes afirmativas. Trata-se de um programa piloto que prevê a distribuiçấo de bolsas de iniciação científica às instituiçôes que preencham esses requisitos e se interessem em participar do programa. Disponível em: http://cnpq.br/pibic-nas-acoes-afirmativas. Acesso em: 09 jan. 2017.

\section{Referências}

ANDRÉS, Aparecida. Aspectos da assistência estudantil nas universidades brasileiras. Brasília, DF: Câmara dos deputados, 2011. Disponível em: <http://bd.camara.gov.br/ bd/bitstream/handle/bdcamara/7284/aspectos_assistencia_andres.pdf?sequence=2.>. Acesso em: 03 nov. 2017.

BORSATO, Francieli Piva. A configuração da assistência estudantil na Universidade Federal de Mato Grosso do Sul após a implantação do PNAES. 2015. Dissertação (Mestrado em Serviço Social e Política Social) - Universidade Estadual de Londrina, Londrina, 2015.

BRASIL. Ministério da Educação e Cultura. Decreto no 7.234, de 19 de julho de 2010. Dispóe sobre o Programa Nacional de Assistência Estudantil - PNAES. Brasília, 2010. Disponível em: <http://www.planalto.gov.br/ccivil_03/_Ato2007-2010/2010/Decreto/ D7234.htm> Acesso em 22 out. 2015.

. Lei de Diretrizes e Bases da Educação Nacional. Brasília, 2007. . Ministério da Educação e Cultura. Decreto no 7.416, de 30 de dezembro de 2010. Regulamenta os arts. 10 e 12 da Lei no 12.155, de 23 de dezembro de 2009, que tratam da concessão de bolsas para desenvolvimento de atividades de ensino e extensão universitária. Disponível em: <http:/www.planalto.gov.br/ccivil_03/_ato20072010/2010/Decreto/D7416.htm>. Acesso em: 30 out. 2018.

CORDEIRO, Maria José de Jesus Alves; CORDEIRO, Ana Luisa Alves. Estratégias de permanência de estudantes na Universidade Estadual de Mato Grosso do Sul (UEMS). In: XXIII Seminário da rede Universitas/Br Políticas de Educação Superior no Brasil: a expansão privado-mercantil em questão. Anais eletrônicos... Belém/PA, 20 a 23 de maio de 2015. p. 831-851. Disponível em: <http://www.obeduc.uerj.br/arquivos/ AnaisRedeUniversitas2705.pdf>. Acesso em: 29 jan. 2016.

FÓRUM NACIONAL DE PRÓ-REITORES DE ASSUNTOS COMUNITÁRIOS E ESTUDANTIS (FONAPRACE). Proposta do Fonaprace. Plano Nacional de Assistência aos estudantes de Graduação das Instituiçôes Federais. p. 01-69, 2007. Disponível em: <http://www.prace.ufop.br/novo/pdfs/fonaprace/LIVRO\%20 FONAPRACE\%2020\%20ANOS.PDF>. Acesso em: 03 nov. 2017. 
GIMENEZ, Felipe Vieira. Expansão e inclusão na educação superior: a bolsa permanência na UFMS. Dissertação de Mestrado. Fundação Universidade Federal de Mato Grosso do Sul. Programa de Pós-Graduação em Educação, 2017. Campo Grande, MS. 2017.

JÚNIOR, João dos Reis Silva; SGUISSARDI, Valdemar. Forma e razóes da expansão da educação superior pública no Brasil. In: MANCEBO, Deise; BITTAR, Mariluce; CHAVES, Vera Lúcia Jacob. (Org.). Educação superior: expansão e reformas educativas. Maringá: Eduem, 2012. p. 21-42.

MAGALHÃES, Rosélia Pinheiro de. Assistência estudantil e o seu papel na permanência dos estudantes de graduação: a experiência da Universidade Federal do Rio de Janeiro. Rio de Janeiro, 2013. Dissertação de Mestrado - Departamento de Serviço Social, Pontifícia Universidade Católica do Rio de Janeiro.

MENEZES, Simone Cazarin de. Assistência estudantil na educação superior pública: $\mathrm{O}$ programa de bolsas implementado pela Universidade Federal do Rio de Janeiro. Rio de Janeiro, 2012. Dissertação de Mestrado - Departamento de Serviço Social, Pontifícia Universidade Católica do Rio de Janeiro.

MACIEL, Carina Elisabeth; LIMA, Elizeth Gonzaga dos Santos; GIMENEZ, Felipe Vieira. Políticas e permanência para estudantes na educação superior. $R B P A E$ - v. 32, n. 3, p. 759 - 781 set./dez. 2016.

MACIEL, Carina Elisabeth; SILVA, Maria das Graças Martins da; VELOSO, Tereza Christina Mertens Aguiar. Assistência Estudantil: a evolução de uma política pública e os significados no contexto da Educação Superior. In: SOUSA, José Vieira (Org.). Expansão e avaliação da educação superior brasileira: formatos, desafios e novas configuraçôes. Brasília: Fino Traço, 2015. p. 255-276.

SGUISSARDI, Valdemar. Estudo diagnóstico da política de expansão da (e acesso à) educação superior no Brasil 2002-2012. Brasília: Edital N. 051/2014 SESU; Projeto de Organismo Internacional - OEI; Projeto OEI/BRA/10/002, 2014.

STOLF, Franciele. Assistência estudantil na universidade federal de Santa Catarina: uma análise inicial do programa bolsa estudantil. Dissertação (mestrado) - Universidade Federal de Santa Catarina, Centro de Ciências da Educação. Programa de PósGraduação em Educação. Florianópolis, Santa Catarina, 2014.

SPOSATI, Aldaiza de Oliveira. Assistência na trajetória das politicas sociais brasileiras: uma questão em análise/ Aldaiza de Oliveira Sposati. et al. 12. Ed. - São Paulo: Cortez, 2014.

UNIVERSIDADE FEDERAL DO MATO GROSSO DO SUL (UFMS). Autoavaliação Institucional da Fundação Universidade Federal de Mato Grosso do Sul. (Relatório ano base 2014) - 2015a. Disponível em: <http://cpa.sites.ufms.br/ files/2016/04/RelatorioParcial_CPA-UFMS_2015.pdf.> Acesso em: 03 nov. 2017. 
- Relatório de Gestão da Fundação Universidade Federal de Mato Grosso do Sul. Exercício 2013. (Pró-reitoria de Planejamento). Campo Grande: 2016. Disponível em: <https://www.ufms.br/universidade/relatorios/relatorios-de-gestao/>. Acesso em: 03 nov. 2017.

- Relatório de Gestão da Fundação Universidade Federal de Mato Grosso do Sul. Exercício 2014. (Pró-reitoria de Planejamento). Campo Grande: 2015b. Disponível em: <https://www.ufms.br/universidade/relatorios/relatorios-de-gestao/>. Acesso em: 03 nov. 2017.

- Relatório de Gestão da Fundação Universidade Federal de Mato Grosso do Sul. Exercício 2015. (Pró-reitoria de Planejamento). Campo Grande: 2016a. Disponível em: <https://www.ufms.br/universidade/relatorios/relatorios-de-gestao/>. Acesso em: 03 nov. 2017.

Resolução, Coun, no 78, de 22 de setembro de 2011. Aprova o Regimento Geral da Fundaçáo Universidade Federal de Mato Grosso do Sul. Campo Grande: 2016b.

. Resolução no 269, de $1^{\circ}$ de agosto de 2013. O conselho de ensino de graduação da Fundação Universidade Federal de Mato Grosso do Sul, no uso de suas atribuiçóes legais, resolve: Art. 10 Aprovar o Regulamento Geral dos Cursos de Graduação Presenciais da Fundação Universidade Federal de Mato Grosso do Sul, nos termos do Anexo desta Resolução.

. Resolução no 7, de 6 de fevereiro de 2015. Aprovar o Regulamento da Ação Bolsa Permanência da Fundação Universidade Federal de Mato Grosso do Sul. 2015c.

. Decreto $n^{\circ} 5.773$ de 09 de maio de 2006. Plano de Desenvolvimento 